\title{
Decision-making: Theory and practice
}

\author{
SM Turpin* MA Marais ${ }^{\dagger}$ \\ Received: 24 June 2004; Revised: 15 September 2004; Accepted: 6 October 2004
}

\begin{abstract}
This paper compares a number of theoretical models of decision-making with the way in which senior managers make decisions in practice. Six prominent decision-makers were interviewed about their own decision-making style, as well as their use of decision support technology. Significant variation was found in personal decision-making styles. However, some central themes emerged, such as the importance of sensitivity to the decision-making context, attention to the presentation of information, and the use of intuition. In terms of the use of decision support technology, the use of self-help tools, such as office software, was clearly favoured.
\end{abstract}

Key words: Decision-making, decision-maker

\section{Introduction}

Decision support consultants are employed or decision support systems (DSS) are implemented in order to support decision-making in an organisation. This assumes that the way in which decision-making actually takes place in the organisation is understood. There are many models of decision-making. People with a background in quantitative analysis would typically have been exposed to rational decision-making methods, such as Simon's (1977) four-step decision model that incorporates intelligence, design, choice and review. This process is often accompanied by the calculation of the subjective expected utility (SEU) or another way of ranking alternatives to facilitate choosing the best option.

It has been observed that the outputs of decision support projects, often packaged as decision support systems, are not used to support decision-making in the way that was intended. This could imply some discrepancy between the decision-making process that is being assumed or modelled and the way decision-making occurs in practice. In order to test assumptions about decision-making and the use of decision support technology, the literature on decision-making was studied and compared to the way that a number of managers make decisions in practice.

\footnotetext{
${ }^{*}$ Corresponding author: CSIR - Defencetek, PO Box 395, Pretoria, 0001, South Africa, email: mturpin@csir.co.za

${ }^{\dagger}$ CSIR - Centre for Logistics and Decision Support, PO Box 395, Pretoria, 0001, South Africa
} 
The paper starts with the introduction of various theoretical models of decision-making. Following this, the results from interviews with a few prominent decision-makers on the topic of decision-making are discussed. A comparison is done between the theoretical models and the extent to which they reflect the actual practices and thinking about decisionmaking by the decision-makers. Subsequently, general insights gained from the interviews are summarised, such as regarding the process of decision-making and how to influence other decision-makers. Other topics that receive particular attention are the use of technology in decision-making and the use of decision support tools.

\section{Various models of decision-making}

Various views and theories of decision-making may be found in the literature. The following list of views, supporting theories and models is based upon categorisations provided by Keen and Scott Morton (1978), Huber (1981), and Das and Teng (1999). Das and Teng's list is, by itself, a meta-classification. The last two items mentioned in the list below, namely naturalistic decision-making and the multiple perspectives approach, are relatively new and did not appear in the mentioned categorisations.

\subsection{The rational model}

The rational manager view assumes a rational and completely informed decision-maker ("economic man") as described by neoclassical microeconomic theory around the middle of the previous century. The process of rational decision-making comprises a number of steps, such as those given by Simon (1977):

- Intelligence: finding occasions for making a decision;

- Design: inventing, developing and analysing possible courses of action;

- Choice: selecting a particular course of action from those available; and

- Review: assessing past choices.

In classical or perfect rationality, methods of decision analysis are used to attach numerical values or utilities to each of the alternatives during the "choice" phase. The alternative with the highest utility (or maximum subjective expected utility) is selected. When using the rational model in this fashion, it is assumed that managers [11]:

- "know of all possible alternatives;

- know the consequences of implementing each alternative;

- have a well organised set of preferences for these consequences; and

- have the computational ability to compare consequences and to determine which is preferred." 


\subsection{The model of bounded rationality}

The "satisficing," process-oriented view is based primarily on Simon's (1979) work on bounded rationality, admitting that the rational manager does not always have complete information, and that optimal choices are not always required. According to Simon (as quoted by Chase et al. (1998)), "human rational behaviour is shaped by a scissors whose two blades are the structure of task environments and the computational capabilities of the actor." These scissors cut the problem space into a much smaller area that is feasible to search. Bounded rationality is characterised by the activities of searching and satisficing. Alternatives are searched for and evaluated sequentially. If an alternative satisfies certain implicitly or explicitly stated minimum criteria, it is said to "satisfice" and the search is terminated. The process of searching might be made easier by the identification of regularities in the task environment.

Although Simon has been highly acclaimed for the theory of bounded rationality, it still describes (albeit constrained) rational behaviour. For this reason, a number of researchers, such as Huber (1981) and Das and Teng (1999), do not distinguish between perfect and bounded rationality in their classification of decision-making models.

\subsection{The incrementalist view}

The logical incrementalist view involves a step-by-step process of incremental actions and keeps the strategy open to adjustment. Under Lindblom's (1959) disjointed incrementalism ("muddling through") marginal, feasible changes are made, working from the status quo to solve existing problems rather than towards goals. Other researchers describe a process of "muddling with a purpose" [6].

\subsection{The organisational procedures view}

The organisational procedures view seeks to understand decisions as the output of standard operating procedures invoked by organisational subunits. March (1988) contributed to this theory. Huber [7] names this view the "program model," indicating that the decisions are pre-programmed in existing procedures as well as the routinised thinking of the people involved. Das and Teng (1999) refer to it as the "avoidance mode" which views decision-making as a systematic process aimed at maintaining the status quo at the cost of innovation. On the other hand, Krabuanrat and Phelps (1998) regard this view in a positive light, namely as the use of codified organisational experience.

\subsection{The political view}

The political view sees decision-making as a personalised bargaining process, driven by the agendas of participants rather than rational processes. People differ on the organisation's goals, values and the relevance of information. The decision-making process never ends, but remains a continuous battle between different coalitions. After one group wins a round of the battle, other parties might regroup or become even more determined to win the next round. Influence and power is wielded in a deliberate manner and to further self-interest. The goals of the coalitions are defined by self-interest rather than by what is good for the 
organisation as a whole. Pfeffer (1981) is one of the major contributors on politics and power in decision-making.

\subsection{The garbage can model}

The garbage can view describes decision-making in an "organised anarchy" and is based on the work of Cohen, March and Olsen (1972). Like the political view, it assumes a pluralist environment with multiple actors, goals and views. The garbage can model emphasises the fragmentedness and chaotic nature of decision-making in organisations, rather than the deliberate manipulations implied by the political view. In the garbage can model, "a decision is an outcome or interpretation of several relatively independent streams in an organisation" [4]. The streams of problems (looking for solutions and opportunities to be aired), of solutions (looking for issues to which they might provide an answer), and of participants (whose attention is divided and who come and go) meet each other at a choice opportunity, symbolised as a garbage can. When a decision is made, the garbage can is removed. This might happen without having solved all or some of the associated problems in the garbage can. Since participants are the ones generating the garbage, or problems and solutions, the decision made is totally dependent on the make-up of the team of participants in the can.

\subsection{The individual differences perspective}

The individual differences perspective focuses the attention on the problem-solving behaviour of the individual manager, as influenced by the manager's decision-making style, background and personality. It tries to explain how managers might use different methods or come to different conclusions because of differing personalities, for example apart from Keen and Scott Morton (1978), the individual differences perspective has not received much attention. This is probably because of the overall emphasis elsewhere on organisational (or group) rather than individual decision-making.

\subsection{Naturalistic decision-making}

Naturalistic decision-making is concerned with investigating and understanding decisionmaking in its natural context. The empirical foundation of naturalistic decision-making differentiates it from other descriptive models, such as the organisational procedures, garbage can or political views. A recent contribution to the field of naturalistic decisionmaking is that of Klein's (1998) Recognition-Primed Decision (RPD) model. Klein observed and/or analysed over 600 decisions made by people in life-or-death situations, such as firemen, nurses and soldiers.

Central to the RPD model is the decision-maker's ability to recognise a situation as being similar to that of a previous experience. Part of what is recognised are the appropriate goals associated with such a situation, as well as important cues and what to expect. Decision-makers also recognise a course of action that is likely to succeed. The course of action is evaluated by means of a mental simulation, where the decision-maker visualises how the action is implemented. The script is revised until the decision-maker is 
comfortable with it, after which it is implemented. All this can happen in a course of a few seconds. If a situation is not recognised as typical, more energy needs to be spent to diagnose the situation, and additional information will be collected. According to Klein, one of the key factors leading to good decisions is experience. The RPD model supports the idea that experience will increase the person's ability to recognise a situation.

\subsection{The multiple perspectives approach}

Mitroff and Linstone (1993) propose the multiple perspectives approach to decision-making as an attempt to "sweep in" all possible perspectives on a problem. It is based on Singer and Churchman's (1971) concept of unbounded systems thinking, which assumes that any problem is a member of any other problem.

The multiple perspectives view classifies perspectives as either being technical, organisational or individual in nature. Analytical models that collect data as a basis of understanding the system, would all fall under the technical perspective. Different analysts or modelling projects will come up with different technical views, even if these projects claim to present an objective or rational picture of the situation. Thus, it is encouraged that more than one technical view of a system is obtained. In order to cover the organisational and individual perspectives, as many as possible of the roleplayers and stakeholders should be investigated. Data collection is also to follow the "sweeping in" approach, and especially the organisational and technical perspectives data need to be gained in multiple modes and from as many sources as possible.

Apart from the technical, organisational and individual views, Mitroff and Linstone (1993) advise that ethical and aesthetical perspectives should also be kept in mind. Even if a decision makes sense from a technical perspective, or if a particular group of organisations endorses it, the decision might not be ethical.

\section{Inputs from decision-makers}

In this section, interviews with a number of decision-makers are discussed. Insights were gained regarding the way the interviewees make decisions, influence decision-making around them, and how their decision-making is supported by technology.

\subsection{Information collection}

Informal interviews were held with six prominent decision-makers. These included people from government, from a parastatal as well as from private companies. The decisionmakers were at levels of seniority ranging from Director to Chief Executive Officer (CEO). Of the six people, five were male and one female. All were graduates (including $3 \mathrm{PhDs}$ ) with qualifications mostly in the pure or applied sciences. Each decision-maker discussed some cases of decision-making that they were involved in, using these cases to illustrate their own views on decision-making. The context of each decision-maker and extracts from the discussion are provided in sequence. 
Interviews were in every case conducted jointly by the two authors. Notes were taken by each author and compared afterwards. No voice recording was done. It was felt that formal recording might have impacted on the information disclosed in existing trust relationships with decision-makers (much off-the-record contextual information was supplied by the decision-makers). Subjectivity and potential incompleteness of records were at least partially managed by the consistent use of the same two interviewers, as well as the fact that a draft of the paper was sent to all decision-makers to confirm that their respective messages were adequately captured.

\subsection{The first decision-maker, DM1}

DM1 has studied in the natural sciences and is perceived to be a structured, analytical thinker. The discussion with DM1 revolved around DM1's experiences as a business unit manager, where decision-making was at an executive level, impacting a business unit. Also discussed was the implementation of strategic decision support processes and tools in DM1's previous work environments, namely in a parastatal and in government. Here, DM1 was involved in processes where stakeholders had to be influenced and in some instances trained in structured decision-making. The following comments reflect the difficulties experienced with implementing structured decision-making in a context where senior decision-makers were involved:

- Although there is a need for improved decision-making in government, there is no stated demand for a more rational approach.

- The usefulness of Think Tools ${ }^{1}$ is to develop understanding of how issues influence each other. This often leads to the problem being presented differently and different or new solutions surfacing.

- A number of attempts to use Think Tools in the governmental environment failed because roleplayers were not interested in a process that would neutralise their own power play.

- Politically powerful people most often make decisions intuitively and might be embarrassed to have the real influences on their decision-making exposed. They are thus wary of structured descriptions of problems. Many also have short attention spans and are not willing to endure the grind of creating the Compatibility Matrix in Think Tools, for example.

- Politicians make decisions to favour their own position, rather than aiming to make good decisions.

\footnotetext{
${ }^{1}$ Think Tools, founded in Germany by Dr. Albrecht von Mueller, aims to make "thinking" more systematic, while improving the quality of decisions and outcomes. It is a suite of ten tools that assesses a given situation, identifies options and risks, visualizes the impact of the decision, and more. Each tool addresses and visualizes the extreme complexity that critical issues can present, and collectively develop hundreds of potential strategies and options. Think Tools is used to identify the strategies, scenarios, options, and risks of implementing a decision. The ten tools build upon one another to enhance the reasoning and thought process [19].
} 
- People do not want to revisit or own up to a "bad" decision. They might explain changes in their behaviour by giving reasons that do not expose mistakes of the past.

- On the use of a feature-rich computer-based Executive Information System (EIS) in a company: only one person is known to use the "executive dashboard".

- Decision-making is about dealing with the irrationalities and uncertainties of a problem (the certainties and rationalities do not require decisions).

- The way in which one persuades a manager to make a decision is more important than the validity of your argument.

\subsection{The second decision-maker, DM2}

DM2 has qualifications in the natural sciences and currently holds a senior position at a government department. One of DM2's roles is to shape the development process of national government strategies in order to achieve acceptance thereof. DM2 is adept at sensing and analysing the organisational and political environment, and is also able to apply appropriate decision-making theories and strategies to the context at hand. The following comments were made by DM2:

- Being effective is not the same as being "right." Rather, one needs to understand the pond in which one is swimming. A strategic decision-maker should be aware of his/her environment rather than focusing on the use of tools. A senior bureaucrat is a sensing organism.

- The function of information is in making the case. Information is a weapon that should be packaged convincingly.

- One needs to look at and respond to what is in a manager's head, and not just focus on the facts.

\subsection{The third decision-maker, DM3}

DM3 holds qualifications in the applied mathematical sciences. DM3 is a process-oriented person who uses a structured mental approach, and is also guided by intuition and values. As CEO of a company, DM3's decision-making roles include the structuring of the company and its relationships with other companies. DM3 often facilitates meetings within or outside the work context. Comments from DM3 include the following:

- There are two issues that bedevil the decision process. The one is uncertainty and the other is the difference in value systems among the people who have to make decisions jointly.

- When facilitating group decision-making, sensitivity to people's value systems is more helpful than the use of tools. 
- In the context of decisions being guided by intuition, one should recognise that the intuition aspect is a very unconscious process, and is influenced by one's own experience.

- Tools are used in "managing mode" rather than "decision-making mode." Self-help tools, such as spreadsheets, allow for quick-and-dirty but extremely useful analyses. In the current business environment, a $60 \%$ solution today is infinitely better than a $100 \%$ solution tomorrow.

\subsection{The fourth decision-maker, DM4}

DM4 has a background in the behavioural sciences and in marketing. DM4 has had diverse work experience, working in industries such as manufacturing, information technology, and a knowledge organisation. Historically, DM4 performed mainly a marketing and business development role, and is currently involved with competence development in a knowledge organisation. DM4 likes to assimilate various theories, and has had exposure to a number of decision-making theories. Reflections by DM4 include the following:

- Two separate cases from different contexts were mentioned where a decision-maker asked a number of parties in the organisation separately to provide proposals on how to deal with the same issue. In the one case, the fact that the decision-maker received eight totally different proposals caused management to come to the realisation that they will need to start introducing multi-disciplinary approaches as well as package their offerings differently. It eventually led to the restructuring of the organisation. In the second case, an executive routinely uses this method in order to gain multiple perspectives on a problem.

- Large organisations tend to feed upon themselves. They do things, because they do things, because they do things...

- The decision-making context needs to be taken into account when supporting decision-making. For example, a marketing situation requires use of the client's frame of reference as a basis. When facilitating group decision-making, one should encourage participation and move towards the line of best fit. When the context is a production process it is likely that optimisation, simulation and quantitative methods are appropriate.

- In DM4's current organisation, staff have often proven themselves to be scientifically clever, but culturally and socially inept when dealing with clients from other regions or backgrounds.

- Being able to listen and respond to a client's needs when a longer-term sustainable relationship is at stake is more important than trying to sell one's offerings as a short-term quick win. Cases were mentioned where consultants were perceived by the client to be too clever for the client and not listening to what the client really wanted. 
- In a successful case study of an EIS, an informal people network was also used as a feedback loop for the decision-maker, while all the operational data was in the EIS. As such, the decision support system did not come between the decision-maker and the people, but supplemented the relationship.

- The path of synergy that one walks with a client is more important in innovationhungry business conditions than the outcome; shared understanding and buy-in is worth more than solely a good end-product that meets specifications of an outdated paradigm.

- Organisations need to be kept responsive; even a network-model organisation becomes stagnant after 18 months and needs renewal by bringing in new nodes. When the organisation becomes stable, there is the risk that its diagnosis of situations (pattern matching) happens too quickly, and new blood can assist in questioning its assumptions.

- When confronted with a situation, DM4 tries to decide whether the situation fits into DM4's existing framework or whether it is something new. If it is the latter, then one should not be afraid to take risks.

- When deciding how to spend the hours in a workday, DM4 evaluates the tasks presented against personal long-term vision and goals (as opposed to just that of the organisation). There should be a match between where one really wants to go and what the organisation requires from one, else there is no meaning in performing those tasks.

\subsection{The fifth decision-maker, DM5}

DM5 is the CEO of a business incubator for software firms. DM5 has qualifications in industrial engineering and business management. Work experience includes management consulting and business intelligence. As an entrepreneur, DM5 established and sold a high technology company. DM5's current role is to influence stakeholders who make strategic decisions about the incubator and to support and guide the companies in the incubator. DM5 is also involved in the development and marketing of a decision support tool through one of the incubator companies. Key characteristics of DM5's decision-making style are an intuitive approach and being comfortable with taking and managing risks. DM5 shared the following insights:

- One of the most common deliverables of a decision support consultant is a report. Decision-makers judge the value of a report by its thickness and professional "look and feel", using thickness as a measure of the amount of homework done by consultants (the thump factor). Such a report is a minimum requirement and does not necessarily contribute to the decision-making.

- One's influence on a decision-maker is dependent on ability to attract and retain their interest. In the light of the previous point, DM5 uses as many graphics as possible in proposals, starting with the cover page. 
- The decision-making process as experienced at a large management consulting company is seemingly very efficient, but flawed due to the fact that their process entails the creation of a hypothesis and then proving it. DM5 believes a decision is only necessary when one can present a number of alternatives that are equally feasible, and that one should focus on the trade-offs rather than trying to persuade people in a particular direction.

- Decision-making in South Africa is of a bad quality; avoiding decision-making is perceived as safer than making a tough decision.

- DM5's decision-making style is intuitive. A situation is explored and decisions taken at the last possible moment, remaining open to new information as long as possible.

- Operational decisions are based on an educated gut feel and experience. Strategic decisions require a more creative process and are shaped while being thought through.

- If a decision has a $60 \%$ chance of success, one needs to manage the $40 \%$ that might make it fail. One needs to distinguish real risks from perceived ones.

- The value of a decision support tool is that it can free up one's mind by taking care of the issues that can be automated or that are well defined already.

- DM5 is an advocate of self-help decision support tools.

\subsection{The sixth decision-maker, DM6}

DM6 is the CEO of a parastatal and has studied mathematics, physics and statistics. DM6 has a background in R\&D management in commercial as well as academic environments. DM6 is a rational decision-maker whose decisions and arguments are based on the rules of logic, and believes that an argument must be defensible in a logical manner. DM6 shared the following:

- DM6's arguments are the result of personal analysis as well as those of other people. Arguments are written out in prose, to see that they are plausible. Stories and anecdotes are used if it is believed that the targeted audience will be able to relate to the story.

- Most people are rational and want to engage with issues that transcend the day-today operational concerns.

- Messiness in the decision environment is reduced by asking: What creates noise? One of the origins of noise is irrational opinion. One needs to define the boundaries of a problem situation: if there are too many dependencies you have to choose a subset of them, and either ignore the rest or assume you cannot change it.

- One should distinguish between decisions that are made on scientific grounds (and as such require inputs from subject matter experts, no matter what their seniority in management is) and management level decisions (such as on operational matters, 
where no expert opinions are relevant). One needs to find a balance between when to assert and when to consult, taking into account the above-mentioned issues. One also needs to accept that some people will never buy in to a decision.

- One needs to be careful in applying business principles in a university environment. Many universities have been around for hundreds of years - before the companies existed on which business principles are based. The same universities will be there after these companies have ceased to exist. Hasty and drastic decisions should not be made concerning such long-term institutions.

- Quantitative analysis tools should be used with great care when addressing qualitative problems. It is, in general, notoriously difficult to defend the mapping of complex qualitative knowledge, instinct and gut feel into quantitative values. The defensibility of such an exercise can be of dubious merit, except in artificially straightforward cases. Correspondingly, the inferences drawn will be of equally dubious merit, despite the often presumed rigour of "doing it by numbers." Also, such tools are open to manipulation to suit one's interests (e.g. by assigning weights).

\section{Discussion}

\subsection{Comparing theory and practice}

The models of decision-making as presented are listed below, together with any evidence of these models being acknowledged by the decision-makers interviewed. Decision-makers were not presented with these models, and the evidence is based on the perceptions of the interviewers. The fact that no evidence of use was found for a particular model, only means that this model never surfaced "naturally" during the discussions.

\begin{tabular}{lcccccc}
\hline Decision-making theory & DM1 & DM2 & DM3 & DM4 & DM5 & DM6 \\
\hline Rational model & & & & & & $\sqrt{ }$ \\
$\begin{array}{l}\text { Bounded rationality and satisficing } \\
\text { Incrementalist approach }\end{array}$ & & & $\sqrt{ }$ & & $\sqrt{ }$ & $\sqrt{ }$ \\
Organisational procedures view & & & & & $\sqrt{ }$ & \\
$\begin{array}{l}\text { Political model } \\
\text { Garbage Can model }\end{array}$ & $\sqrt{ }$ & $\sqrt{ }$ & & & & \\
Individual Differences perspective & $\sqrt{ }$ & & & & & \\
Recognition-Primed Decision Model & & $\sqrt{ }$ & $\sqrt{ }$ & $\sqrt{ }$ & & \\
Multiple perspectives approach & & & $\sqrt{ }$ & $\sqrt{ }$ & & \\
\hline
\end{tabular}

Table 1: Evidence of use of decision-making theories.

The rational model was supported by only one person. DM6 uses rational arguments and assumes that reasonable people would also be rational in their thinking. On the other hand, the rational model was explicitly criticised by DM1 for its failure to resolve issues in a politicised environment, where the "best" decision or a rational decision process is ruled out in favour of people's own interests.

Support for bounded rationality and a "satisficing" approach was found in DM3's and also to an extent DM5's reference to the use of e.g. spreadsheets in a self-help mode. The 
concept of satisficing was supported by these two decision-makers when they stated that a $60 \%$ decision today is better than a perfect decision sometime in the future. DM6 believed that one should isolate a subset of the system and work with that, thus having a more manageable set of variables and interdependencies.

The organisational procedures view was referred to by DM5. DM5 criticised some aspects of the way decisions are typically made (or not made) in organisations. He also made it clear that one needed to understand how decision-making processes work in order to influence them (for example, how proposals or research reports are considered and evaluated).

The political model was strongly supported by DM1 and DM2, who emphasised that sensitivity to the political context in which the decision needs to be made and the ability to respond to and survive in that environment, overrules the correctness of a decision.

Individual differences were referred to by DM1, who asserted that many decision-makers could be classified as introvert, intuitive, thinking and judging (INTJ) on the Myers-Briggs personality type indicators, and who then proceeded to explain their decision-making behaviour in the light of this.

The Recognition-Primed Decision Model was supported in the sense that decision-making was seen by DM2, DM3 and DM4 to be a process strongly influenced by intuition and experience. Situational awareness, which was perceived to be significant, is also a feature of the Recognition-Primed Decision Model.

The multiple perspectives approach was supported in spirit by DM3 and DM4, who recognised that people come to the decision-making table with multiple value systems and viewpoints. Also, it pays to use multi-disciplinary teams to do problem-solving and to gather multiple views on an issue. Support and implicit use by the six decision-makers interviewed of the decision-making models or theories described in $\S 2$ are summarised in Table 1.

\subsection{Personal style vs. the decision-making environment}

Decision-makers did not just describe their own decision-making, but also how they experienced decision-making to occur around them. Often, their own actions were a response to what happened in their environment - for most of them, influencing the decision-making of the people around them was one of their key functions. The essence of people's own styles as well as their perceptions of the respective environments is presented in Table 2. Although elements of each of the different styles were observed in more than one person, for some people it featured as an overriding characteristic, and they will thus be labelled with such a description. For example, DM1 preferred a rational decision-making process, but observed that the decision-making environment was political and hence mentioned decision-practices which we could classify as shown in Table 2.

Some frustration was sensed with decision-makers whose personal style and that of their environment were not easily reconcilable. DM1 may be used again as an example: DM1 preferred a rational style, but realised that rationality had limited influence in a political environment. 


\begin{tabular}{lll}
\hline & $\begin{array}{l}\text { Decision-maker's } \\
\text { personal style }\end{array}$ & $\begin{array}{l}\text { Perception of decision- } \\
\text { making environment }\end{array}$ \\
\hline DM1 & Rational & Political \\
DM2 & Political & Political \\
DM3 & Intuitive; value-based & Multiple perspectives view \\
DM4 & Multiple perspectives view & Dependent on context \\
DM5 & Intuitive & Organisational procedures view \\
DM6 & Rational & Rational \\
\hline
\end{tabular}

Table 2: Comparison between personal style and perception of decision-making environment.

\subsection{The use of technology in decision-making}

Regarding the use of technology to support their own decision-making, the message that emerged most strongly was the decision-makers' reliance on self-help desktop technology, such as commonly used office software (e.g. MS Office, Open Office). Spreadsheets are used for numerical analyses, word processors to construct arguments and presentation packages to construct visually convincing arguments. Technology is also used for information collection, which is performed by means of web search tools and electronic accessing of journals. Although an awareness exists of more sophisticated DSS tools, their use by the six decision-makers appears to be limited. The following appears to be a common phenomenon as is explained by DM5: 25000 copies of Expert Choice have been sold worldwide, compared to 350000 copies of MindManager. There is a continuum of decision support tools with self-help tools such as Powerpoint on the one end (requiring just-in-time learning and used by the manager) and sophisticated tools such as SAS (where an expert is required) on the other end. The latter set of tools is very expensive and is only used where greater precision is required.

The above description may be illustrated graphically as in Figure 1.

\begin{tabular}{|c|c|}
\hline High volume of sales & Low volume of sales \\
\hline Affordable price & Very expensive \\
\hline Not data intensive & Data intensive \\
\hline Can be used by a novice & Expert training required \\
\hline $\begin{array}{l}\text { Gives "good enough" answers / } \\
\text { analysis quickly }\end{array}$ & $\begin{array}{l}\text { Gives more precise answers } \\
\text { but takes longer }\end{array}$ \\
\hline Self-help tool & Sophisticated DSS tool \\
\hline $\begin{array}{l}\text { Office software, } \\
\text { mind mapping tools }\end{array}$ & $\begin{array}{l}\text { Data mining and business } \\
\text { intelligence tools }\end{array}$ \\
\hline
\end{tabular}

Figure 1: Comparison of self-help and sophisticated decision support tools.

It was clear that DM5, as well as most of the other people interviewed, attached a higher value to self-help tools than to sophisticated decision support tools. In particular, DM5 was concerned with the long turnaround time associated with the use of data-driven tools: by the time the appropriate data have been identified, captured and analysed, the situation might have changed already. Concerns from other decision-makers included that the logic in DSS tools could easily be manipulated to support a particular argument, and that people in a politicised environment do not necessarily want to improve the rationality and 
transparency of their decision-making process.

\subsection{Insights into the process of decision-making}

The decision-making process of several of the decision-makers may be described broadly as having two phases: a divergent, exploratory phase and a convergent phase where the focus is to reduce the number of alternatives and then make the decision. This is similar to the decision process described in Russo and Schoemaker (2002), consisting of expansive and convergent phases: The divergent phase is described as a creative phase where alternative solutions are generated. One of the decision-makers referred to the strategy of tasking four different people to analyse the same problem. Another approach is to ask different business units to scope a solution in isolation or to use multi-disciplinary teams that have different perspectives to interact with each other. Personal style and background also plays a role. Some decision-makers acknowledge the role of the subconscious in order to develop new solutions; others refer to this process as being intuitive.

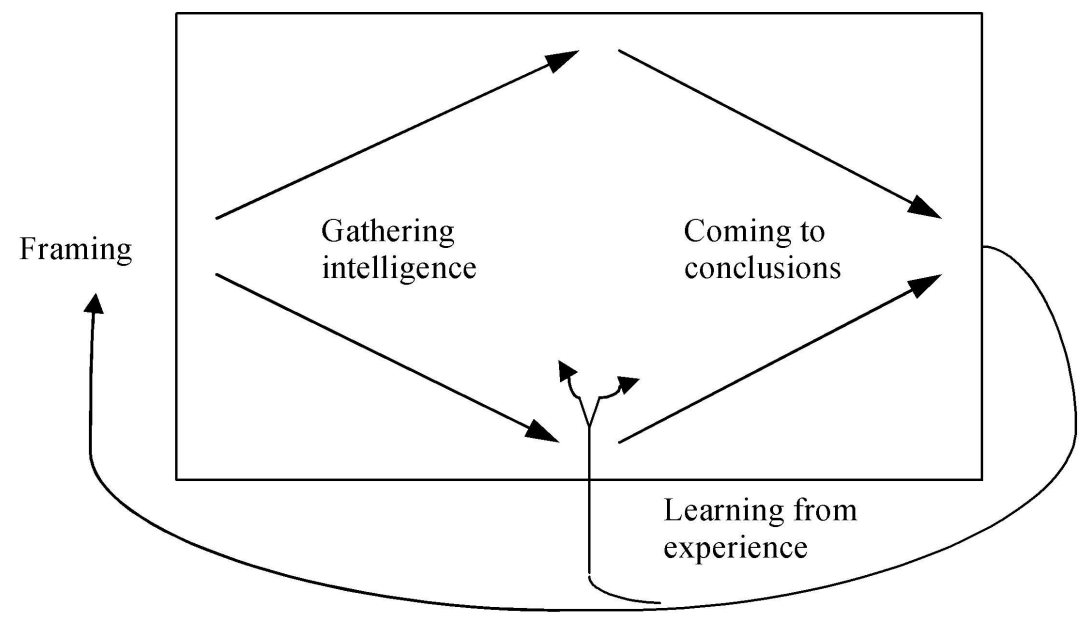

Figure 2: Stages of the decision process [16].

This divergent phase corresponds to the Design step in Simon's (1977) model of rationaldecision-making, where possible courses of action are developed. This is also the phase in which the multiple perspectives approach of Mitroff and Linstone (1993) can be applied to good effect.

At some point the process has to converge toward a decision. In the convergent phase it seems that personality and perceptions play an important role. If the decision-maker is not afraid of living with uncertainty and the situation is dynamic, the convergent phase will be postponed in order to keep options open until the last moment. If it is important to the decision-maker to be seen to be decisive and not dithering, this phase needs to be as short as possible. The balancing act is how to remain open to new information that may impact the decision materially, without delaying the decision unnecessarily. One could wait forever and still not have all of the information to ensure a correct decision. The balancing act may also lead to a cycling between the divergent and convergent phases; the 
overall process is not necessarily a linear one.

The overall process is dependent on many factors, such as the complexity of the problem, the time pressure and the environment. For example, in a business environment the pressure is greater to compress the two phases and move on to the next decision. In an academic environment many interests need to be considered and a consultative process is used that diverges more and converges slowly. A consultant may be driven by budget constraints to cut short the divergent phase, and, possibly, by the need to deliver "concrete results" as soon as possible. In an emergency situation one cannot afford to wait too long before acting.

\subsection{Influencing decision-making}

Key lessons from the above decision-makers who are influencing decision-making (whether to improve it or to further their own ends) may be summarised as follows.

\section{Understanding the context}

Firstly, one needs to understand one's environment, or decision-making context. Successful approaches include a deliberate classification of people, situations or organisational processes into existing frameworks, being sensitive to people's value systems, being a sensing organism that attempts to respond to what is inside a manager's head, and the use of gut feel or intuition.

\section{Packaging of information}

Decision-makers are typically overloaded with information and need to be guided towards the message one wants to communicate. The consultant may be requested to deliver a thick report, but this is not necessarily used to base decisions on. Packaging of information in more visually appealing and digestible formats can assist in getting across a written message. However, the verbal communication process should also receive attention. Communication is a two-way process. In this context, a decision support consultant should keep the following questions in mind: Am I listening and responding to a client's real need or am I focusing on what I have to sell? How do I attract and retain people's interest? How good are my persuasion skills?

\section{Self-help technology}

It needs to be acknowledged that tools, such as the MS Office suite, are more readily available and understood than most analytical decision support tools. If a manager is given a spreadsheet to experiment with, the chances might be better that it will be used.

\section{Conclusion}

This study attempted to provide the decision support consultant with some insight into the decision-making style of individual decision-makers as well as that of organisations. Only when such decision-making is understood can one claim to truly support it. In the field of Operations Research, the scientific method [1] is used to provide decision support. Often, this means a focus on the rational components of decision-making. Although analytical decision support tools may be extremely useful in solving problems in a complex and 
industrialised environment, the same tools or methods cannot necessarily be applied to human decision-making. Even the seasoned decision-makers surveyed, most of whom had a highly analytical background, do not rely on formal decision support tools to a large extent. Indeed, one of the surprises of this study was that although a number of the decision-makers had formal training in sophisticated decision support methods and technology, some selling it to clients or stakeholders, they found limited use for it in their own environments. In the conversations, issues such as the appropriate use of gut feel and sensitivity to the political context often took precedence over the rational aspects of decision-making. The results of this study seem to indicate that rather than following the normative approach that attempts to improve the rationality of human decision-making, there might be merit in the support of an approach that is descriptive, focuses on the human process and assumes that people are competent decision-makers.

The study shows that attention to aspects such as the decision-making context, the nature of the decision-making processes, people's personal styles, the agendas of decision-makers, as well as the presentation of results, may significantly improve the impact of a decision support project. It also raises the question of how decision support consultants can develop a sensitivity towards the various models of thinking about decision-making so that they do not fall into the trap of reducing problems to fit their preferred models.

One of the models of decision-making that received relatively strong support, in principle, was that of the Recognition-Primed Decision (RPD) model describing naturalistic decisionmaking. This was mainly because the RPD model recognises the use of, among others, gut feel and intuition as part of the decision-making process. The RPD model was based on the behaviour of people in crisis situations with severe time constraints. One suggestion for further research would be to investigate how the RDP model could be adapted for organisational decision-makers who might have more time to reflect and consult, but where the impact of decisions is still severe.

\section{Acknowledgements}

We wish to thank the six decision-makers who have kindly and generously made available the time for us to pick their brains, and who have also assisted in reviewing this paper. In addition, the two anonymous referees are acknowledged for their substantial contribution in enhancing the quality of the paper.

\section{References}

[1] A Career in operations research, 2002, Pamflet distributed by the Operations Research Society of South Africa.

[2] Chase VM, Hertwig R \& Gigerenzer G, 1998, Visions of rationality, Trends in Cognitive Sciences, 2(6), pp. 206-214.

[3] Churchman CW, 1971, The design of inquiring systems: Basic concepts of systems and organization, Basic Books Inc., Ney York (NY). 
[4] Cohen MD, March JG \& Olsen JP, 1972, A garbage can model of organisational choice, reprinted in: MARCH JG, 1988, Decisions and Organizations, Basil Blackwell, Oxford.

[5] Courtney JF, 2001, Decision-making and knowledge management in inquiring organizations: Toward a new decision-making paradigm for DSS, Decision Support Systems, 31, pp. 17-38.

[6] DAS TK \& TENG BS, 1999, Cognitive biases and strategic decision processes: An integrative perspective, Journal of Management Studies, 36(6), pp. 757-778.

[7] Huber GP, 1981, The nature of organisational decision making and the design of decision support systems, Management Information Systems Quarterly, June 1981.

[8] Keen PGW \& Scott Morton MS, 1978, Decision support systems: An organisational perspective, Addison-Wesley, Reading (MA).

[9] Klein G, 1998, Sources of power: How people make decisions, MIT Press, Cambridge (MA).

[10] Krabuanrat K \& Phelps R, 1998, Heuristics and rationality in strategic decision making: An exploratory study, Journal of Business Research, 41, pp. 83-93.

[11] Kreitner R \& Kinicki A, 2001, Organizational behaviour, $5^{\text {th }}$ Edition, Irwin McGraw Hill, Burr Ridge (IL).

[12] Lindblom CW, 1959, The science of muddling through, Public Administration Review, 19(2), pp. 79-88.

[13] March JG, 1988, Decisions and organizations, Basil Blackwell, Oxford.

[14] Mitroff II \& Linstone HA, 1993, The unbounded mind, Oxford University Press, New York (NY).

[15] Pfeffer J, 1981, Power in organisations, Pitman Publishing, Marshfield (MA).

[16] Russo JE \& Schoemaker JH, 2002, Winning decisions: How to make the right decision the first time, Piatkus, London.

[17] Simon HA, 1977, The new science of management decision, $2^{\text {nd }}$ Edition, Prentice Hall, Englewood Cliffs (NJ).

[18] Simon HA, 1979, Rational decision making in business organisations, American Economic Review, 69(4), pp. 493-513.

[19] Think Tools, [Online], [Cited 27 May 2004], Available from

http://www. thinktools.com/ 
